\title{
Learning by Solving Problems: Cognitive Load Theory and the Re-Design of an Introductory GIS Course
}

\begin{abstract}
This article presents a teaching model to support learning by solving problems with geographic information technology. Using the case study of a re-designed introductory course in geographic information systems, I present research from studies of expertise and Cognitive Load Theory that identify learning objectives and methods for problem-based instruction. I illustrate a general template for learning geographic technology by solving a problem based on a process of understanding the problem, developing a plan, and implementing the plan. This template also reinforces learning during practice and exam problems. The article aims to encourage future research on problem-based instruction of geographic information technologies that integrate cognitive studies of learning, spatial thinking, and problem solving.
\end{abstract}

\section{INTRODUCTION}

THERE ARE GOOD instructional resources for those who ask the question, "How can I develop a GIS\&T curriculum that works?" (Prager 2011, 64). But as a junior member of a department, the question I needed answered was slightly more modest: "How can I re-design components of a course that I have inherited from a colleague in a way that preserves what works while improving what could work better?”

In spring 1987, Bob Churchill began offering a course titled "Cartography/Graphics" in the Geography Department at Middlebury College. Churchill viewed computer-based cartography as a "profitable pedagogical tool," one that "can be used to illustrate many basic spatial and cartographic concepts far more emphatically and convincingly than conventional classroom approaches" (Churchill and Frankland 1981, 69). In 1990, Churchill renamed his course "Geographic Information Systems" after the pedagogical tool that he used. He designed his course to introduce students to spatial analysis and cartographic design by showing them how to use GIS tools to solve authentic problems. He presented these tutorials live, during a three-hour laboratory meeting. At the end of each lab, he gave a homework assignment that required students to solve a problem that was analogous to the inclass tutorial in many ways, but also presented some small twist where the solution he showed in class wouldn't work and the students had to trouble-shoot independently. By 1999, his course had been made a requirement for all majors in both the Department of Geography and the Program in Environmental Studies. Then in late October 2004, Bob called a colleague in the department to tell him he wasn't feeling well enough to make it to class that day. On November 14, 2004, nine weeks into the fall semester, Bob Churchill passed away.

In 2007, I arrived at Middlebury, fresh from graduate school, to teach Bob's class. I received eight labs that descended from Bob's course, but no other teaching materials. There were no lab notes, no explanations for the content, and no lecture materials to accompany the laboratory tutorials. So I studied the labs like rare artifacts. Why did he spend the whole lab period demonstrating how to solve one long problem before students worked independently? How could he have presented the tutorials in ways that would help the students digest the depth of content that they contained? What made a problem different from the tutorial in a way that gave it a good twist?

This article shares answers to some of these questions and aims to help instructors who are engaged in the design of instructional materials that support learning while solving 
problems with geographic information technologies. In the next section, I review research in expertise and cognitive load theory that point to learning objectives and strategies for problem-based instruction. Next, I present my revisions to Bob's teaching model to support problem-based learning in an introductory GIS course. The discussion section connects the framework to (1) general kinds of knowledge that characterize expertise, and (2) evidence-based methods for instructional design from cognitive load theory. The discussion concludes by connecting the framework to future research questions in cartographic education, including applications for teaching cartographic design.

\section{LEARNING BY SOLVING PROBLEMS}

“The Strawman Report” $(2003,13)$ posits problem solving as a core component of learning GIS, arguing that it is "essential for academic programs to emphasize the practical aspects of the GIS\&T domain along with the theoretical ones... Central to all paths is the development of problem identification and problem solving capabilities." But the report does not offer instructors much specific guidance for doing this. Similarly, the Body of Knowledge for Geographic Information Science and Technology (DiBiase et al. 2006) that followed the Strawman Report provides a rich list of desideratum to define levels of competency with geographic information technologies, but doesn't offer prescriptive advice to help teachers support this learning.

So as I began to redesign Bob's course, I started with a basic question: what do students do when they solve problems? Duncker (1945) defines a problem as a situation that arises when an agent "has a goal but does not know how this goal is to be reached."

Whenever one cannot go from a given situation to the desired situation simply by action, then there has to be recourse to thinking. (By action we here understand the performance of obvious operations). Such thinking has the task of devising some action which may mediate between the existing and desired situations.

This suggests that problem solving is the thinking that students must learn to do when they don't know what to do. It also suggests that when students can do something without thinking about it, then the thing that they are doing is no longer a problem for them. Applied to the technology we teach, the latter point is presumably a basic learning objective for most GIS instructors: we'd like our students to be able to do things with geographic information technology without having to think a lot about the software itself. In Marble's (1998) pyramid of competency, this constitutes the first operational level ("if an operation is accessible from the interface tool bar, then the individual should be able to handle-and understand - it without too great an effort").

But the first point is more challenging. How can instruction help students learn to think through a problem with a GIS? As an instructor, the issue is two-fold. First, what are meaningful learning objectives for "problem identification and problem solving capabilities" that transcend skills that are specific to software? Second, how can instruction support learning and not make learning more difficult?

\section{THINKING THROUGH PROBLEMS}

To get at the first question, I began by asking: how do experts differ from novices when solving problems? This question can be approached in at least two different ways and each reflects a different metaphor of learning (Sfard 1998). One way is to identify kinds of knowledge that experts seem to possess and that novices do not possess. This frames learning with an acquisition metaphor, as something that learners can acquire, construct, and transfer. An alternative approach is to compare what experts seem to be able to do while solving problems that novices cannot do. This frames learning with a participation metaphor, as something that experts do rather than have, and as something embedded in practice. Below, I briefly follow both routes to outline learning objectives that can be drawn from each.

The first path considers expertise as domain-specific knowledge that experts acquire over years of experience. In an insightful review of research in physics, computer programming, and medicine, Mayer (1992) identifies four key differences between experts and novices. First, experts seem to understand facts differently than novices, where 
facts are basic knowledge of a domain. Experts seem to store this basic knowledge in larger units and can access it more rapidly than novices. Second, experts seem to understand the semantics of tasks differently than novices. They are more likely to recognize conceptual underpinnings of problems, while novices are more likely to focus on surface features. Third, experts seem to understand the schematic structure of a problem differently than novices. This can be observed be comparing how experts and novices sort problems. Experts are more likely to discriminate problem types with categories that reflect a principle-based plan for solving problems, while novices are more likely to sort based on surface features of problems. Fourth, experts seem to understand strategies for generating and monitoring solutions differently than a novice. Experts tend to employ large chunks of knowledge to plan solutions, while novices are less likely to work forward through a solution with a plan while considering alternatives.

Dana Tomlin's (1990) textbook on cartographic modeling neatly illustrates each kind of knowledge in the domain of problem solving with a GIS. Factual knowledge is illustrated by his description of "Cartographic Models" (2-23). A cartographic model consists of map layers, which have a title, resolution, orientation, and zones; zones have a label, value, and locations, and so on. For Tomlin (an expert), a map layer consists of all these lower-level facts. A student who uses this textbook (novice) will likely learn each lower-level fact individually and slowly associate them into larger chunks. Semantic knowledge is illustrated by Tomlin's description of "Relationships Between Cartographic and Geographic Space" (24-45). Here, he begins to explain reasons for measuring distances between the center points of cells and reasons for measuring length based on relationships of a location to its eight neighbors. The semantics of these tasks are revealed by Tomlin's explanations that are based on relationships between spatial concepts and cartographic models. Schematic knowledge is illustrated by Tomlin's taxonomy of local, focal, and zonal operations (64-165). He sorts GIS operations into groups based on underlying spatial principles. Strategic knowledge is illustrated by his discussion of "more sophisticated techniques" that involve "combining selected operations into procedures that are tailored to the needs of particular applications." These are similar to routines in computer programming and evidence a means of organizing knowledge about solutions in larger chunks organized around higher-level goals.
Another way of framing expertise is to examine what experts seem to be able to do rather than focus on the kinds of knowledge that experts seem to possess. For Schön (1983, 53-55), expert practitioners are often able to do things without thinking about them, without being aware of having learned how to do these things, and without even the ability to describe what it is that they know that allows them to act. This tacit knowledge he calls "knowing-in-action" and, importantly, it is something learned through practice and not through the conscious application of principles. In addition, he describes the ability of expert practitioners to think on their feet, to learn by doing, or to think while acting, which he categorizes as "reflecting-in-action." This again emphasizes what experts know to do, rather than what knowledge they have, and also situates this active knowing in a particular problem context.

As Sfard (1998) notes, the importance of recognizing two different frames for learning from or through experience is not to choose one as superior over the other, but rather to encourage instructors to incorporate the ideas of both in their design of learning environments. For me, the two together help shape objectives for both acquiring knowledge and learning by doing. For the former, objectives include helping students organize facts, explain how and why operations work, compare and contrast different problems, and develop plans for solving them. For the latter, objectives include helping students learn to do things without thinking about them, enable incidental learning through action, and encourage reflection while problem solving.

A final issue common to both frames of learning concerns how to guide students through the process of solving problems. Pólya (1971) recognized that learning to solve mathematical problems requires some thoughtful guidance by teachers, and he provides a useful template to support learning by problem solving. He suggests teachers should guide students through four phases of problem solving. First, help students understand the problem. This includes recognizing the goal, the initial states, and the conditions. Second, help students devise a plan by looking for analogies between the current problem and ones that have been solved previously. Third, help students carry out the plan and monitor each step to check if it is correct or as they expected it. Fourth, help students reflect on their result and the solution that obtained it, examining if there may be alternative ways to derive the result and whether 
there are parts of their solution that they might be able to use elsewhere.

\section{COGNITIVE LOAD THEORY}

While I developed these learning objectives, I also sought a framework to help understand learning as a cognitive process and how instruction may influence this process. I could sense that there were at least two components of Bob's teaching model that students found difficult. First, students struggled to connect lecture content to the labs. Second, students struggled to keep up with the live tutorials. It was difficult for them to click along with the tutorial, take notes, and connect software tools with deeper aspects of problem solving all at the same time. I wanted to understand if the difficulty lay in the material itself or if it instead had to do with the way that I presented the material to students, or perhaps in some combination of the two. I found Cognitive Load Theory (Plass, Moreno, and Brünken 2010) to be particularly useful because it considers ways in which the intrinsic content of material, the way an instructor presents this content, and the way that novices solve problems all interact to influence learning. In this section, I briefly outline the theoretical framework and the strategies it offers instructors for supporting learning while problem solving.

At first glance, Cognitive Load Theory (CLT) appears firmly embedded in the acquisition metaphor of learning. CLT views learning as an active process, involving the integration of new information with previous knowledge and the construction rather than the replication of knowledge (Bartlett 1932). Sweller (2010) calls this the "borrowing and reorganizing principle" of learning: we borrow information from other people's memory and then reorganize it by assimilating this new information with things we already know. CLT posits that learning involves the construction of general knowledge structures called "schemas" that we construct in working memory and then store in long-term memory (Figure 1). While the capacity of long-term memory appears to be quite vast, the capacity of working memory is limited. CLT largely concerns how the limited capacity of working memory, as well as the previous knowledge stored in long-term memory, can affect how we use and acquire knowledge.

With respect to how we use knowledge, CLT posits that schemas held in long term memory can be processed in two ways. The first is unconscious processing,

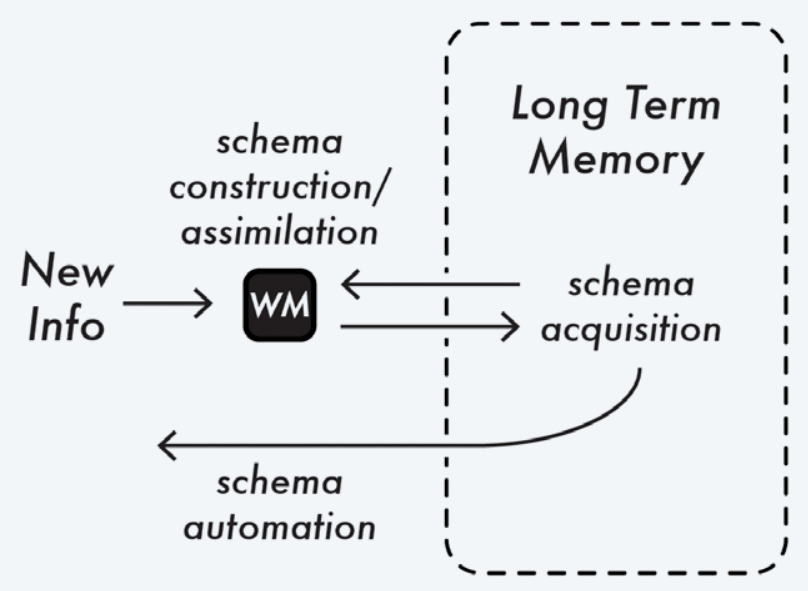

Figure 1. Cognitive Load Theory assumes a model of learning based on schema construction in Working Memory (WM), schema acquisition in Long Term Memory, and schema automation from Long Term Memory.

or something done without thinking and without placing load on working memory. In CLT, this process is called "schema automation" or "automatic processing." This is distinct from "controlled processing," which occurs in working memory and is characteristically slow, conscious, and limited (Schneider and Shiffrin 1977). Thus, although the jargon used to describe learning within a CLT framework fits easily with the acquisition metaphor of learning, it does not necessarily exclude the participation metaphor, or at least the kinds of knowing described by Schön (1983). Automatic processing bears similarity to knowing-in-action, as both involve knowing without thinking. Additionally, controlled processing seems similar to reflecting-in-action.

With respect to how we acquire knowledge, CLT distinguishes three basic types of demands that learning places on cognitive processing systems (Moreno and Park 2010). Intrinsic load results from the process of representing the content that needs to be learned and deals largely with the inherent complexity, or the number of elements and their interactions or relationships between them that must be held in working memory at the same time during schema construction. Extraneous load results from elements that occupy a learner's working memory which are independent of (and not essential to) the content to be learned and are instead attributed to the presentation of the information. Whatever capacity of working memory that is not occupied with intrinsic or extraneous load then has the potential to be germane to the goal of schema acquisition and 
automation. This germane load results from the active work of constructing and acquiring schemas.

A common goal of research guided by CLT is to identify instructional strategies that minimize extraneous load on problem solvers in order to better enable the processing demands of intrinsic and germane loads. In CLT, these strategies are called "effects" because they have been empirically verified to affect learning outcomes.

The worked-example effect describes a decrease in extraneous load that can result when novices study a complete description of a solution (Sweller and Cooper 1985; Ward and Sweller 1990; Renkl and Atkinson 2010). Worked examples do not simply show students the answer. Rather, they share with students the process of thought entailed to solve the problem. Comparisons of learners who studied conventional problems and worked-examples have found that those who study worked-examples have better learning outcomes with respect to transfer performance, or higher performance reached with less time studying problems and with less mental effort (Paas and Van Merriënboer 1994). Worked examples are not common in GIS education, but have been studied extensively in other domains, including statistics (Paas 1992; Quilici and Mayer 1996), algebra (Sweller and Cooper 1985; Carroll 1994), geometry (Paas and Van Merriënboer 1994), databases (Tuovinen and Sweller 1999), and design (Rourke and Sweller 2009).

Worked examples are most successful when they employ additional methods for presenting instruction that reduce extraneous load. One method is to present elements in integrated formats rather than in isolation. This is most important if the learner needs to hold the elements together in working memory in order to construct and acquire a schema. This is called the split attention effect (Chandler and Sweller 1991; Sweller and Chandler 1994; Sweller et al. 1990). Another method is to replace multiple instances of information that present the same content and can be understood in isolation with a single source. This is called the redundancy effect (Chandler and Sweller 1991; Sweller and Chandler 1994).

There is also some evidence that the germane load of worked examples can be improved with additional methods. One method is to present worked examples that contain task variability. This helps foster comparison of problem types and is called the variability effect (Paas and Van
Merriënboer 1994). Another method encourages students to imagine a procedure or task after studying a worked example presentation. This is called the imagination effect. It appears to helps learners automate previously constructed schemas when compared to methods that require learners to study a worked example without requiring them to close their eyes and imagine it (Cooper et al. 2001; Ginns, Chandler, and Sweller 2003; Leahy and Sweller 2004).

Another key insight from CLT concerns the limitations of the worked example and other associated effects that arise due to the previous knowledge a learner may bring to the classroom. The expertise reversal effect occurs when strategies that decrease extraneous load for novices have the opposite effect on learners with more domain expertise (Kalyuga et al. 2001; Kalyuga et al. 2003). It appears that the worked example effect is strongest for novices. As learners develop domain expertise, providing them detailed descriptions of solutions can be extraneous and increase working memory load. It requires them to process additional information that is not germane to schema construction and acquisition. As a result, guidance fading strategies aim to minimize negative effects by sequencing instruction from worked examples to independent problem solving (Renkl et al. 2002; Renkl and Atkinson 2003). Often guidance fading strategies wean learners from worked examples by asking them to complete one or more missing steps in an otherwise worked-out solution, called the completion effect (Paas and Van Merriënboer 1994).

A common goal for all of these strategies is to enable $e x-$ planation activities as part of the solution process (Chi et al. 1989). Renkl (2010, 233) identifies several general strategies for eliciting explanations that connect to three kinds of knowledge that characterize expertise (Mayer 1992, 387-414). In principle-based explanations, a learner explains an underlying domain principle for an operation or set of operations (semantic). In goal-operator explanations, a learner identifies goals achieved by operators and recognizes relationships between goal structures and operator sequences (strategic). In example comparisons, a learner compares and contrasts the deep or functional structure of different examples (schematic).

At this point, we've discussed the following components to guide the design of problem-based instruction with geographic information technologies: 
1. Frame learning objectives with types of expertise drawn from both acquisition and participation metaphors of learning

2. Guide students through stages of problem solving
3. Present information with methods that manage cognitive load

The next section illustrates how I implemented these components in my redesign of Bob's course.

\section{A TEACHING MODEL TO SUPPORT LEARNING BY SOLVING PROBLEMS WITH GIS}

The TEACHing MOdel I currently use maintains two central components of Bob Churchill's original model: (1) a worked-example method to introduce GIS tools to students in the context of solving geographic problems, and (2) task variability by presenting students nearly analogous practice problems following the introductory tutorial problem. The two major changes I made to this teaching model are (1) to present the worked example as three stages of problem solving, and (2) to present the software tutorial as a pre-lab assignment. Figure 2 illustrates the main components of the teaching model. The vertical axis shows the three types of problems presented to students (tutorial, practice, exam). The horizontal axis represents three phases of problem solving (understand, plan, implement). The tone of each shape represents fading in a social dimension from instructor-led (black) to collaborative (hatched) to independent (hollow). The orientation of each shape represents sequencing in a transfer dimension, or the degree to which the problem is analogous to the first problem, from nearly analogous with a slight twist (only a slight rotation) to a problem that involves a situation that is not analogous to a tutorial problem (a large rotation).
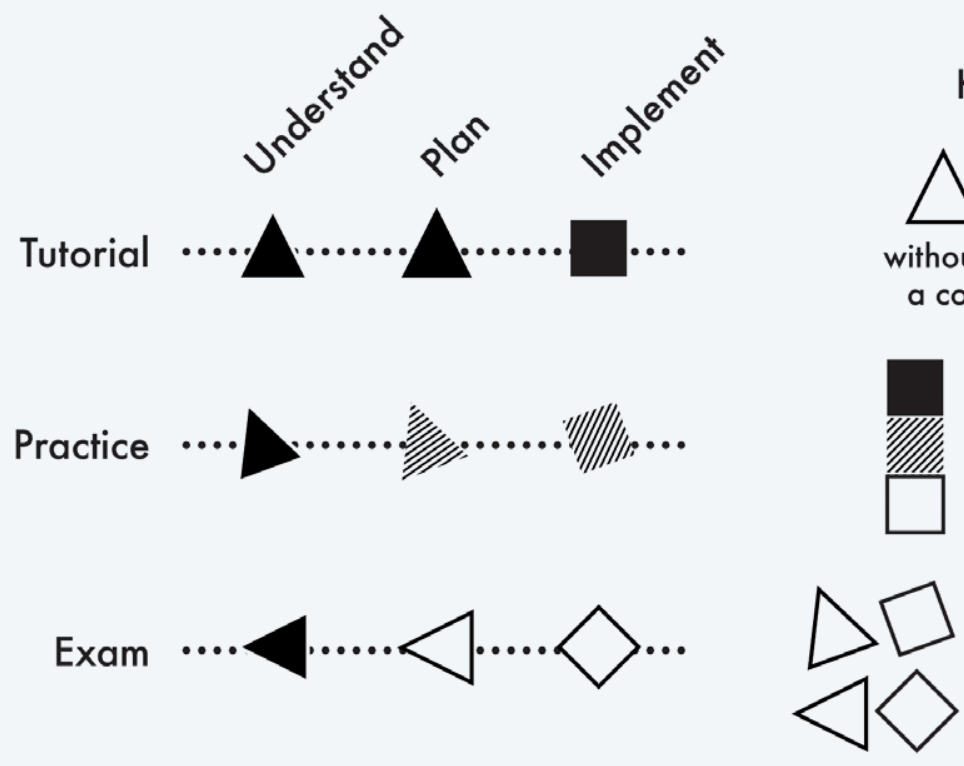

KEY
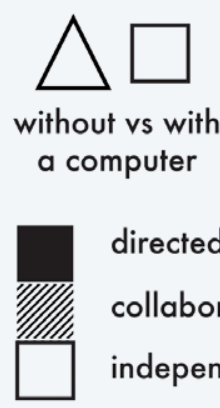

directed

collaborative

independent

nearly analogous

less analogous
Both objectives aim to focus attention away from surface features of the problem and towards the problem's deeper structure. For the first, I try to help students identify descriptions of the goal state, the initial state, and the conditions. To do this, I mark up the problem with different colors to distinguish different components and encourage students to do the same. Using an overhead projector or a digital tablet, I use different colors to underline or highlight the goal state, the initial states that are given to them, and the conditions or constraints that are given to them (Figure 3).

Figure 2. Teaching model for learning to solve problems with GIS. 
On college campuses, planners often use parking lot designations to discourage first year students from bringing personal vehicles to campus. This aims to encourage students to spend more time on or near campus, and also to encourage ridesharing with friends or with public transportation when exploring the region. Your task is to identify parking lots

$\begin{array}{ll}\text { GOAL } & \begin{array}{l}\text { with public transportation when exploring the region. } \\ \text { on college-owned land that could be used for parking by the } 225 \text { students in the freshman } \\ \text { dormitory. The parking lots should be large enough to accommodate one car per dorm } \\ \text { resident, but they should require the students to walk at least } 1 / 4 \text { mile from the dorm to } \\ \text { access their vehicles. In your model, use the American Planning Association's recommenda- } \\ \text { tion that parking lots should allocate } 300 \text { square feet of space per car (this includes space } \\ \text { to park the car and also for the lanes to access the parking spot). We provide you with } \\ \text { two raster layers to use in this analysis. One represents locations that can be used for } \\ \text { student parking on campus with Boolean values (1 if students can park at that location, } 0 \text { if } \\ \text { they cannot). The other represents the location of the single college dormitory that houses } \\ \text { first year students, also with Boolean values. }\end{array} \\ \text { INITIAL }\end{array}$

Figure 3. Help students recognize functional components of a problem's verbal description.

For the second learning objective, I draw schematic diagrams of the spatial relationships that define the problem's key conditions (Figure 4). I tend to draw the pictures in front of the students, rather than just flash pre-made graphics on a screen, as I find that this helps encourage students to draw along with me. Thus the graphics in Figure 4 are a bit more crisp-looking than what students would see on the blackboard.

\section{PLAN TUTORIAL SOLUTION}

The next stage involves developing an initial plan for solving the problem. We continue this discussion in lecture. The four learning objectives are to:

1. Decompose a problem into a hierarchy of sub-tasks

\section{Map general functions to specific operations}

3. Develop good representations of each sub-goal

4. Organize tasks into a sequence of moves to be implemented

For the first objective, I first show students how to decompose the goal into a series of sub-tasks by focusing on telic ("in order to") relations of goals (Figure 5a). For example, I ask, "In order to find lots that meet both area and distance conditions, what two things must we know first?" That should lead to two sub-tasks: find lots that satisfy area condition and find lots that satisfy distance condition. We continue this decomposition activity until we bottom at the initial states that were given to us. At this point, we reflect on the structure of the task hierarchy in order to
INITIAL STATES

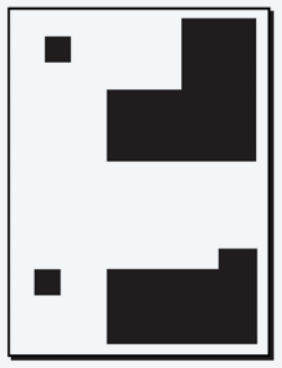

Campus Parking Lots

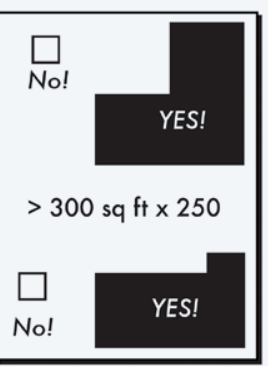

Area Criterion

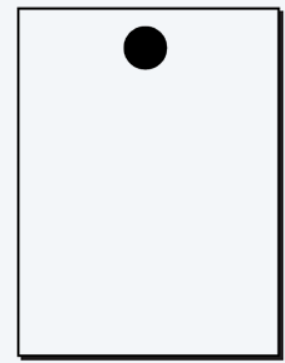

1 st Years' Dormitory CONDITIONS

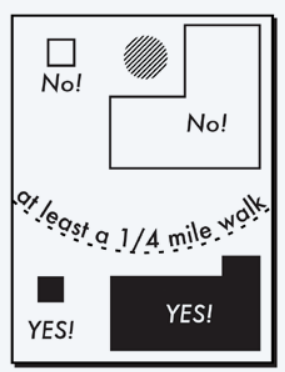

Distance Criterion

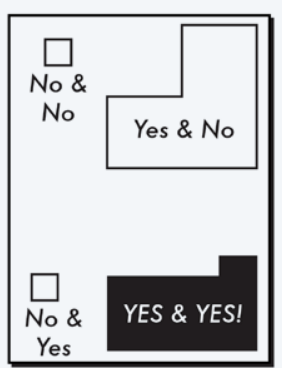

Multi-Criteria
Figure 4. Helping students develop pictorial representations of a problem's functional components.

recognize how sets of tasks suggest larger chunks of the procedure. In this example, we can connect three chunks of tasks to the three conditions visualized during problem representation.

Next, we focus on mapping specific tasks to general functions that can be described with key terms (Figure 5b). To do this, I have students compare a task to related subtasks and ask students, "What seems to be the key term that appears in the goal description but not in the related sub-goals?" This should encourage students to identify 
vernacular terms for the function of each goal. For example, "and" is the key term in the first goal as it doesn't appear in the two related subtasks. This activity creates a list of vernacular words that identify the function of each task that we can then map

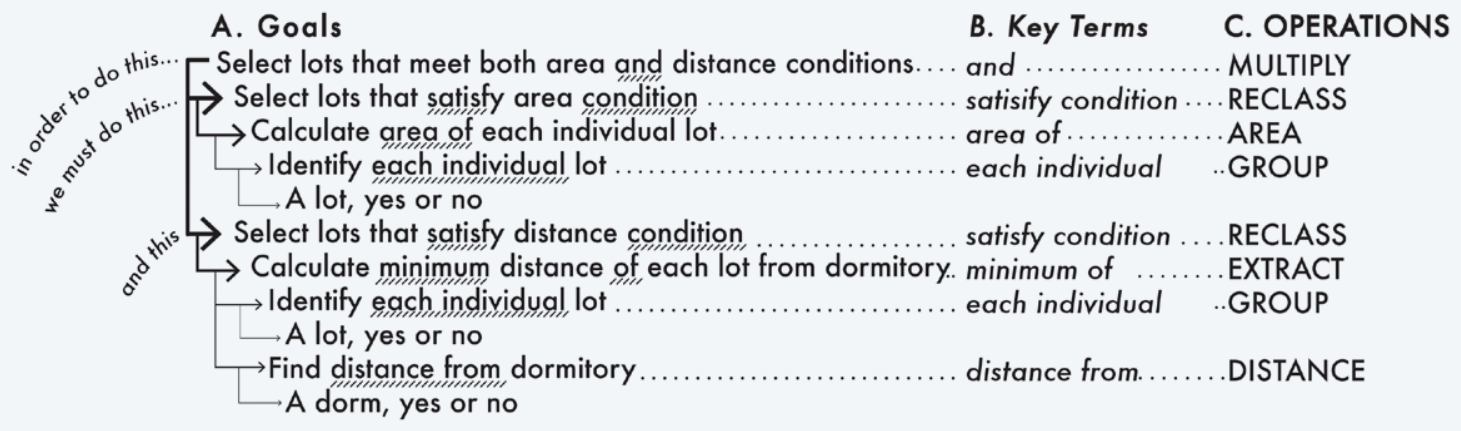

Figure 5. A verbal task hierarchy that maps vernacular key terms to technical operations.

to technical terms for each tool (Figure 5c)

INITIAL STATE

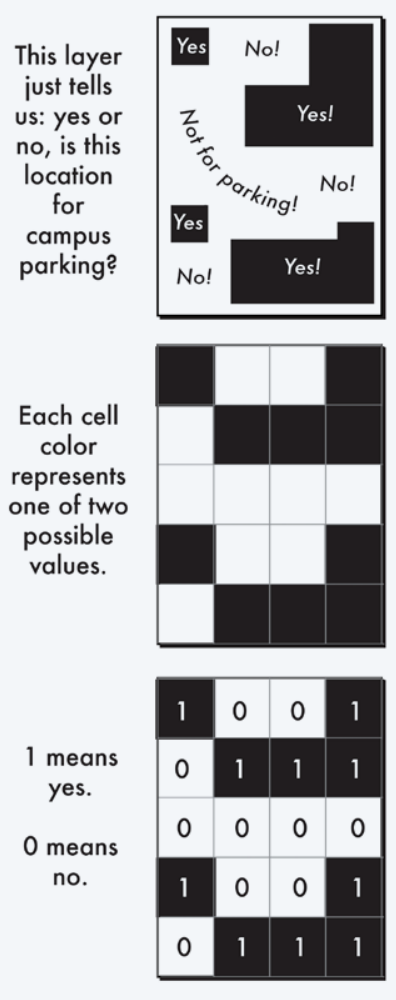

C O N D I T I O N S
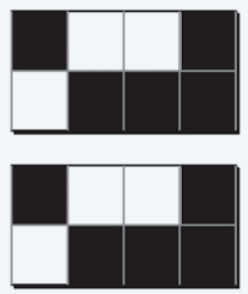

$G \circ A$ L
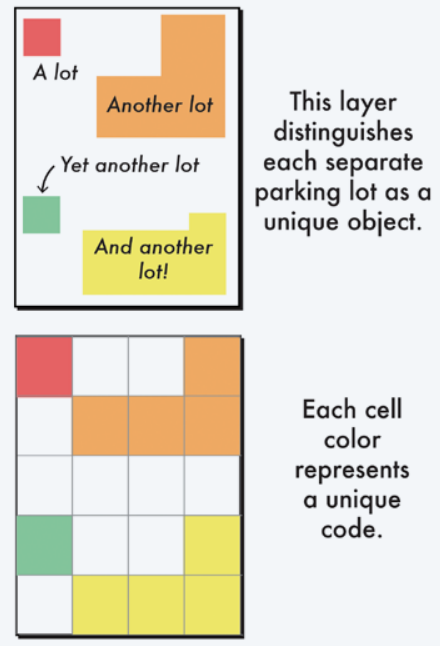

Each cell color represents a unique code.

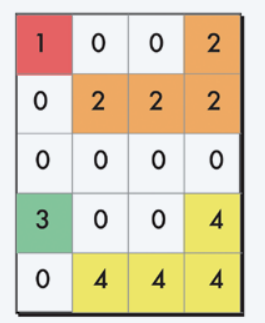

Integers are like unique names. 0 represents all locations that are not lots. thinking about how task hierarchies can influence seto planning solutions: (1) identify connections between tasks, (2) make the solution efficient by removing steps, and (3) determine a sequence. (The busy-looking Figure 7 shows these three components all at once, though I tend to draw them for students in a sequence.) I encourage students to think about planning a workflow as something akin to writing: first focus on making an initial draft and then consider how this might be improved through revisions. As a first draft, we draw a workflow diagram that transcribes each task and shows relationships between them. Figure 7 shows this with black ink. In our revision, we focus on ways to make the solution more efficient by eliminating steps that will not affect the answer. Figure 7 illustrates this with red ink. Third, we explore principles for ordering actions in a workflow by considering how 


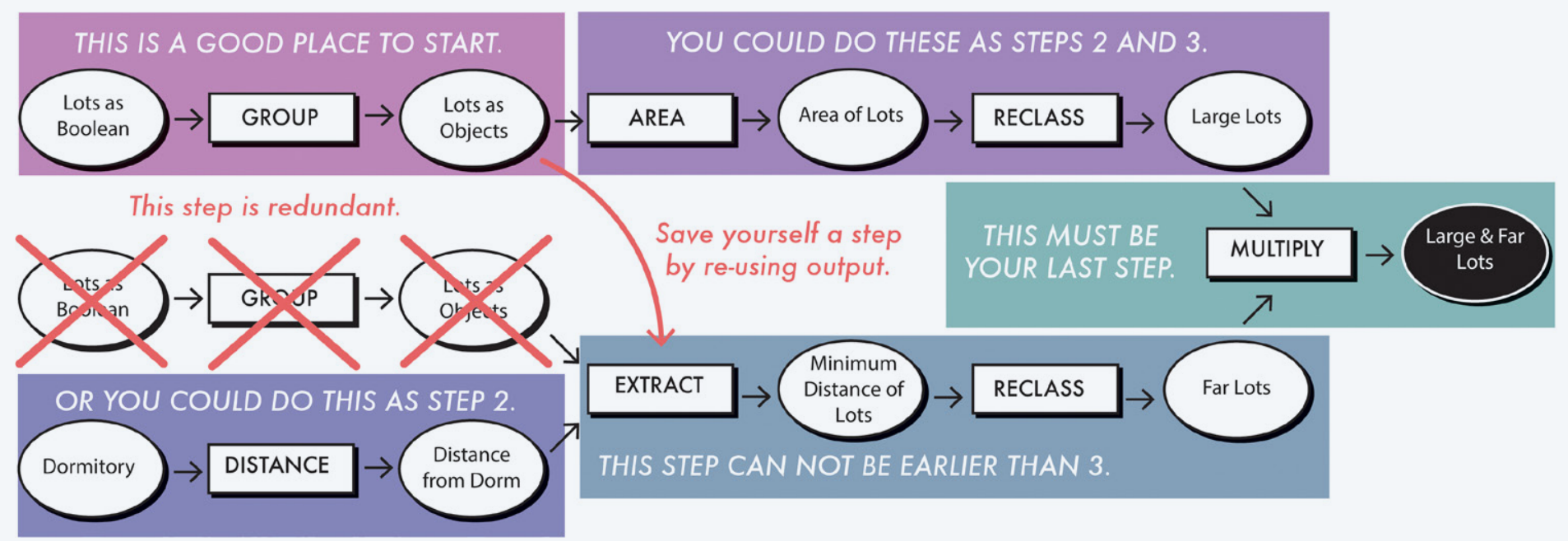

Figure 7. Help students think through three phases of workflow planning: initial draft in black, revisions for efficiency in red, sequencing in twilights.

all steps in each branch have been completed. We can also see that nothing about the problem's structure controls which of these two branches gets taken up first.

\section{IMPLEMENT TUTORIAL SOLUTION}

The next stage involves implementing the plan to solve the problem. Students study these learning materials as homework in preparation for our laboratory meeting. The two learning objectives are:

1. To learn routine tasks of navigating the GUI and of operating tools

2. To monitor the solution implemented with respect to the plan

To implement solutions, I make video tutorials that combine a spoken narration with a screen capture of my interaction with the software to help guide students through the graphic user interface of the software and help them connect these actions back to the plan for solving the problem. This allows students to study the tutorial at their own pace and gives them time to take notes while they follow along. Students are required to study these materials before coming to our lab meeting. To help students connect these actions with the plan, I use the task hierarchy to segment these software tutorials (Figure 8). Each video provides a worked example for how to execute one step in the plan. The playlist does not show how to use a tool twice. When students can produce correct answers by implementing the plan with computer software, they are required to take a short quiz. This also provides incentive to study the plan and implementation materials.

\section{PRACTICE PROBLEM}

With the practice problem, instruction fades from directed, or instructor lead, to collaborative problem solving. The understand, plan, and implementat phases of the practice problem all occur in the computer laboratory. I encourage students to work in pairs or small groups of not more than three. The learning objectives of this stage are to:

1. Support learning through task variation

2. Foster self-explanations during each stage of problem solving

The means to these ends consists of a new problem that in most parts has an analogous structure to the initial 
training problem. The surface features differ and there is at least one part of the problem that is not analogous with the tutorial problem. For example, I often use a variant of this island biogeography problem following the first-year student parking lot problem.

In 1967, Robert MacArthur and Edward Wilson published a monograph titled The Theory of Island Biogeography. The theory posited that certain biological characteristics of islands, such as the number of resident species, could be predicted based on the island's area and distance from the mainland. The "area effect" posited that the rate of extinction would be inversely related to the island's area: extinction rates would be higher on smaller islands than on larger islands. The "distance effect" posited that the rate of immigration would be inversely related to the island's distance from the mainland: immigration rates would be higher on islands near the mainland than on islands far from the mainland. Jared Diamond (1969) tested the theory, using bird species lists from California's Channel Islands. Using the raster layer named "CA_borderland," please make a single map layer that codes each Channel Island based on both distance and area. Classify the islands with $20 \mathrm{~km}$ increments for distance $(<20,20-40$, etc $)$ and a log scale for area $\left(1 \mathrm{~km}^{2}\right.$, $10 \mathrm{~km}^{2}, 100 \mathrm{~km}^{2}$, etc). The final layout should show the mainland and show each island with a single code that represents both the distance class and area class.

What makes this problem different than the tutorial problem? First, the surface features are different. We're dealing with islands and the mainland rather than parking lots and dorms. We're also concerned with the movement of critters rather than first year college students. Second, the initial condition and the goal state are both different. Students will need to separate the mainland and islands as separate layers in this problem and they will need to figure out how to develop a coding scheme that uses one value to represent two attributes. But the key spatial relationships that define the problem's conditions do not differ from the practice problem. The mainland and islands are all disjoint, as were the dorm and parking lots. Because of this, the middle part of the solution is directly analogous to the tutorial problem.

In the laboratory meeting, students are required to complete each task in the three-phase workflow presented in the tutorial. They are required to check in with an instructor after they have completed their plan and then again after they have completed their implementation. Through these interviews, the instructor aims to elicit explanations from students. Questions may include:

- Example comparisons: $Q$. Why does your plan differ from the plan for the tutorial problem? $A$. We need to separate the mainland from the islands because you didn't provide them on separate layers like last time. And we need to use addition here to combine the area and distance classes rather than multiply them.

- Goal-operator explanations: $Q$. What would happen if you had calculated the area of islands without first doing the GROUP step? $A$. I would calculate the area of the entire archipelago rather than each individual island.

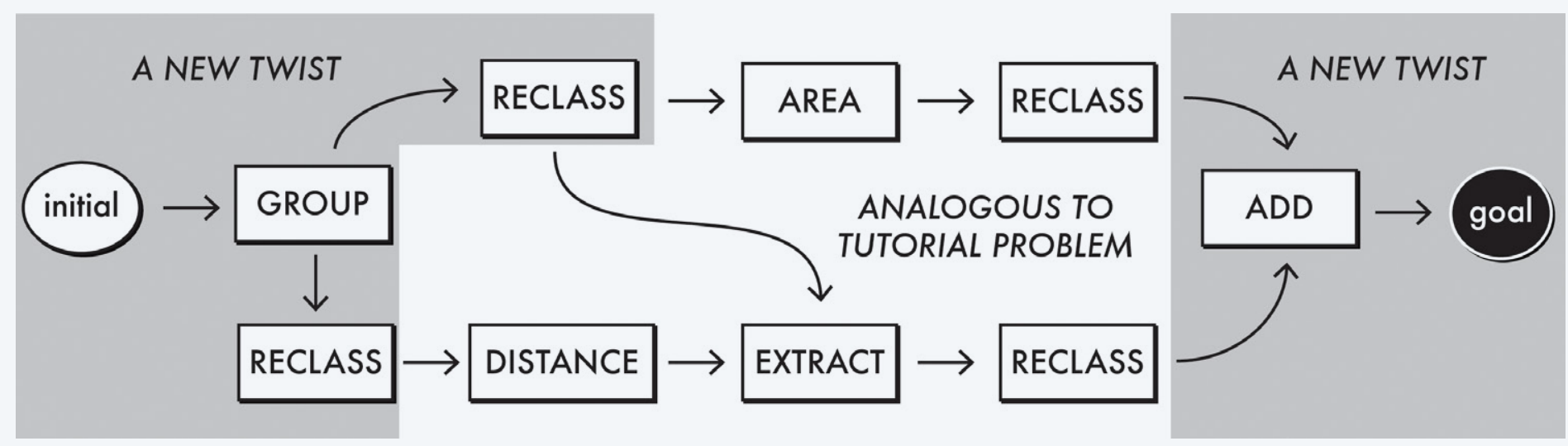

Figure 9. Plan for practice problem. Conditions are analogous to tutorial problem. Initial states and goal present new twists. 
- Principle-based explanations: $Q$. Will you be able to see any of the small islets that surround these islands in your final answer? $A$. If they are smaller than the square of the cell size, then probably not.

After implementing their plans, the students are then required to show their answers to an instructor and correct any mistakes if necessary. When they have arrived at the correct answers, the instructor again engages the students in the final reflection stage of problem solving.

- Example comparisons: $Q$. How does this workflow differ from the tutorial? $A$. It's pretty similar, we just used addition rather than multiply at the end. And we defined classes differently in the steps before that.

- Goal-operator explanations: $Q$. Why are the cells immediately adjacent to the mainland feature never less than $100 \mathrm{~m}$ distance? $A$. The minimum distance from the target is the cell size of the raster layer.

- Principle-based explanations: $Q$. Do you think the area that you calculated might overestimate or underestimate the area of the islands? $A$. Well, on one hand you could say it underestimates it because it calculates planimetric area rather than surface area. But on the other hand, it basically adds together chunks of 10,000 square meters, so maybe that overestimates things?

When students have arrived at the correct answer, presented the answer in the requested layout, and provided satisfactory answers to the prompts, they have completed this part of the instruction.

\section{EXAM PROBLEM}

After three or more weeks of cycling through tutorial and practice problems, I give students an exam that aims to both assess their learning in the course up to this point while also proving an opportunity for them to continue to learn. Exam problems (I generally give two) have some analogies with tutorial and practice problems. One exam problem will also involve a twist that results from a novel spatial relationship in the problem conditions. For example, consider this problem:

When driving on a road, your cell phone call will likely be dropped when you drive across a coverage zone boundary (or at the first pixel on the road that is immediately adjacent and outside of a coverage zone). Given a layer that shows the number of cell towers that can be "viewed" from every location in the state and another layer that shows state highways, make a table that reports the number of pixels on each road where your call would likely get dropped. Don't worry about the direction you may be driving, just report the total number of pixels on each road that are immediately adjacent to and outside of a coverage zone. Assume that if at least one tower is visible at a pixel, then that pixel is in a coverage zone.

This problem can be solved in five steps or fewer with tools that the students learned in the tutorial and practice problems described above, but many students struggle mightily with the problem. To solve it, they must work out a new spatial relationship in the problem conditions that differs from those they have previously encountered (Figure 10). In CLT language, they have not acquired schemas for solving all parts of this problem and must engage in the construction of a new schema without guidance.

As Figure 2 indicates, the exam is again structured around three phases. The exam begins with a presentation of each problem by the instructor. I tend to draw schematic pictures of the problem's conditions, helping students with this one part of understanding the problem in order to draw their attention to the key condition of the problem. I also provide students with pictures of the real datasets, including pictures of the metadata (cells size, extent, reference system, data schema, etc.). Students then have a period of time to develop plans for solving the problems. They are asked to complete a detailed workflow (input-operation-output diagrams) and detail all parameters for each operation that may affect the outputs. They are permitted to experiment with their plan using any of the data from the tutorials and practice problems from previous weeks, but do not have access to the exam datasets during this planning phase.

After several days, we meet again and students submit the original materials from the planning phase (workflow descriptions). They have been instructed to save a copy of these materials for the next phase. I then make the datasets available and students have a window of time to implement their plans. Ideally, they can implement their 


\section{Tutorial and Practice}

\author{
DORM or \\ MAINLAND
}

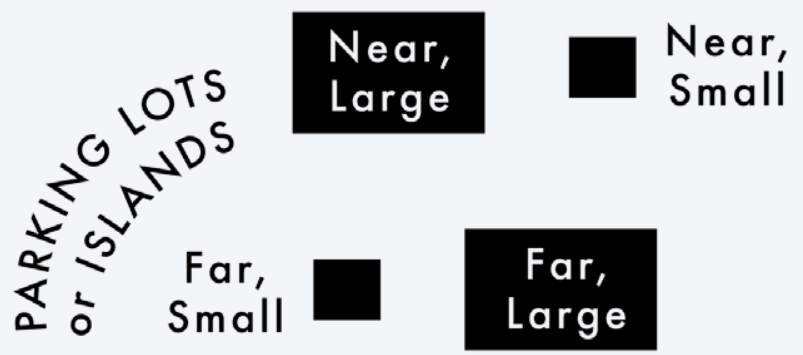

\section{Exam}

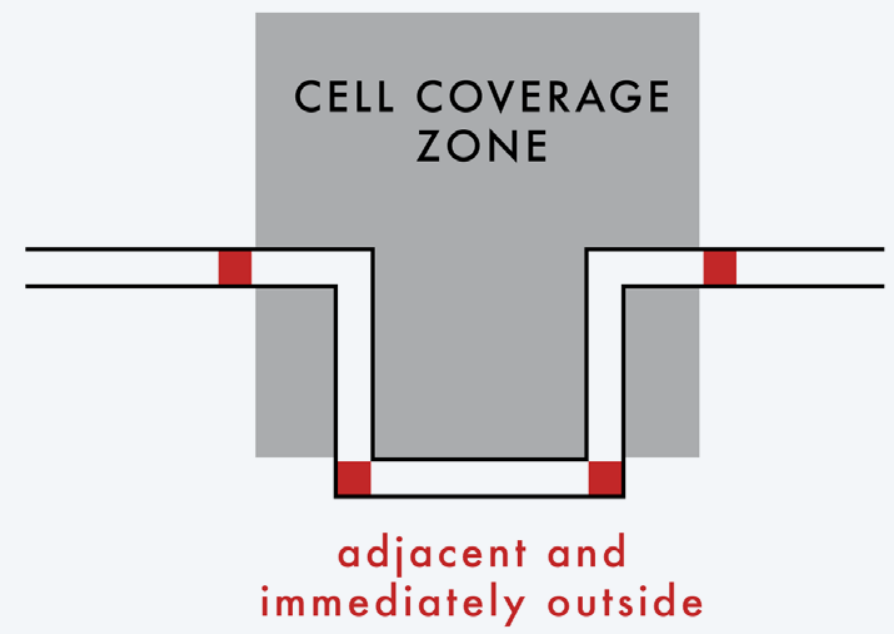

Figure 10. Conditions for one exam problem present a twist from conditions learned in tutorial and practice problems.

plans without any changes and arrive at the correct answer, but this case is usually quite rare. If their plan needs some adjustments, they are required to make the necessary corrections on their copy of the original workflow or, if the corrections are quite extensive, on a new worksheet.

After a couple days, we meet again and students submit the answers to the problem along with their corrections to their plans, if necessary. I then share with students the correct answers to the problems and discuss possible solutions and common errors. If students did not submit the correct answers in their implementation materials, then they are required to write a verbal description of each error that remained in their implemented plans and to demonstrate to an instructor that they understand how to produce the correct answers to both problems. When they have submitted these final corrections, they have finished the exam.

Thus at the end of the exam, we have sampled each student's understanding of GIS at three different moments during the process of solving the problems. This establishes a simple assessment framework. Figure 11 shows four general groups of learners. The top group develops a correct solution during the planning phase. The lower group submits plans with some errors, but can correct these errors independently once they are able to interact with the problem datasets. The answers and plans they submit at the implementation phase are both correct. The next group submits implementation materials with incorrect answers and errors in workflow, but once they can discuss the problem with an instructor, they are able to explain their

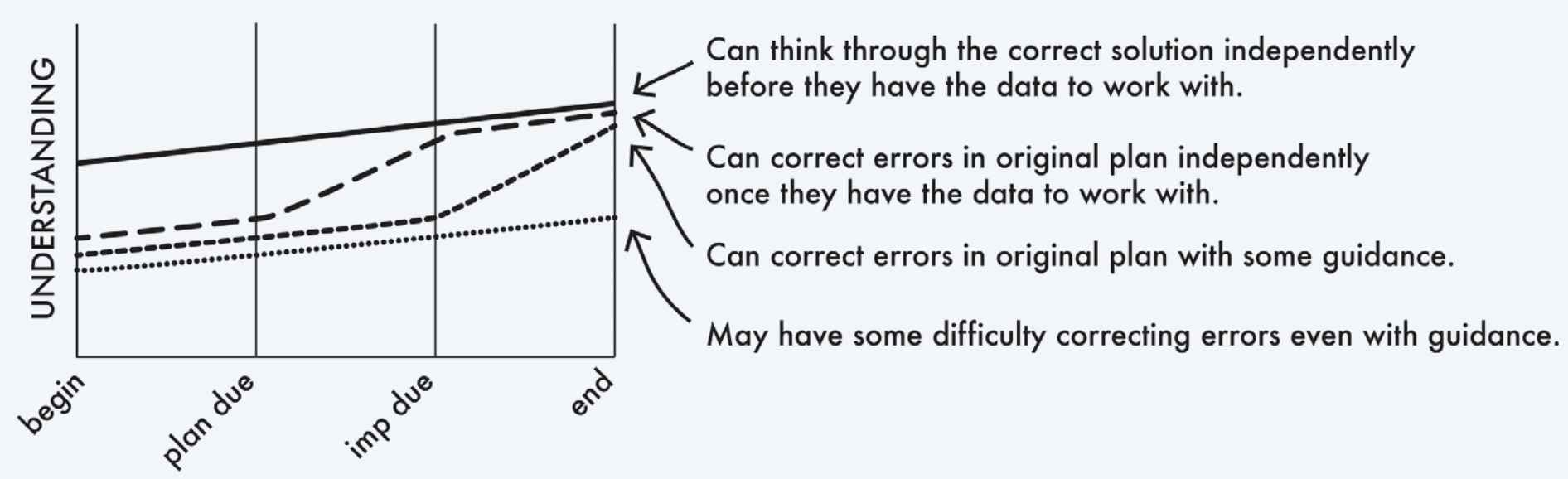

Figure 11. Assessment framework for exams. 
errors and demonstrate that they can implement solutions that produce the correct answers. The final group may still have difficulty with this final part of the exam, struggling to correct errors and perhaps failing to ever produce the correct answers.

\section{DISCUSSION}

I PRESERVED TWO main components of Bob Churchill's original course: presenting a tutorial that showed students how to solve a problem with a GIS and providing analogous problems with some twists in practice and exam problems. Both of these components are, in theory, supported by principles from cognitive load theory. In theory, the tutorial as a worked example should help students devote cognitive resources to learning factual, semantic, strategic and schematic knowledge associated with the problem. This is because the students won't have to devote cognitive resources to naïve problem solving strategies, like means-ends analysis, that focus attention on minimizing differences between the present state and the goal state. In theory, presenting students with analogous problems that contain different twists (or non-analogous components) should also help schema construction based on the variability effect.

One substantive change to the teaching model involved expanding the worked example into three stages (and creating moments of reflection) in tutorial, practice, and exam problems. This represents my attempt to establish a general template for a worked example that involves GIS but transcends the use of the tools themselves. Table 1 outlines the main learning objectives of each stage and connects them to different kinds of knowledge and knowing that they aim to support. Hopefully, this helps distinguish the worked example method from the practice of teaching "cookbook" labs. In the latter, the instructor merely provides students with click-by-click instructions for solving a problem given the specific software the instructor has chosen to teach. As I use the term, a worked example aims to support learning factual, semantic, schematic, and strategic knowledge, while also providing opportunities to learn tacit knowledge during the implementation phase, and conveys all of this as kinds of thinking that guide the clicking of a solution.

The second change to the teaching model did not alter the substance of the course but rather changed the mode of presentation. The video tutorials re-package content that Bob had formerly presented as a live demonstration into a format that students can study at their own pace. Video provides viewing controls (pause, rewind, forward, and variable playback speed) that allow students to cater instruction more to their individual needs. Students can pause to take notes, rewind if they miss a step, and stop when they are tired and want a break. In theory, allowing students to self-segment the instruction into small, reviewable chunks lowers the intrinsic load of the instruction. Furthermore, students can also watch on double-time if the content seems familiar or they can choose to skip entire sections. In theory, this provides a means to lower the extraneous load of instruction that may arise from expertise reversal for advanced students.

Videos present words as spoken narration and pictures as animations. This differs from the more traditional strategy of providing lab instructions as printed text and static images. Future research on how the presentation of words

\begin{tabular}{ll}
\hline Understand Problem & \\
\hline Recognize functional components & Strategic \\
\hline $\begin{array}{l}\text { Develop complementary verbal \& } \\
\text { pictorial models }\end{array}$ & $\begin{array}{l}\text { Semantic, } \\
\text { Schematic }\end{array}$ \\
\hline Plan Solution & \\
\hline Decompose hierarchy sub-tasks & Strategic \\
\hline $\begin{array}{l}\text { Map general functions to specific } \\
\text { operations }\end{array}$ & Factual, Semantic \\
\hline $\begin{array}{l}\text { Develop good representations of sub- } \\
\text { goals }\end{array}$ & $\begin{array}{l}\text { Factual, Semantic, } \\
\text { Schematic }\end{array}$ \\
\hline Organize tasks in sequence & Strategic \\
\hline Implement & \\
\hline Learn routine tasks and data structures & $\begin{array}{l}\text { Factual, Strategic, } \\
\text { Knowing-in-action }\end{array}$ \\
\hline Monitor solutions & $\begin{array}{l}\text { Strategic, } \\
\text { Reflecting-in-action }\end{array}$ \\
\hline
\end{tabular}

Table 1. Learning objectives of worked examples and different kinds of expertise that they support. 
and pictures influence learning can be informed by multimedia learning theory (Mayer 2009; Mayer 2014), which bears some similarities to CLT. Furthermore, the teaching model presented here may be useful for instructors who are considering teaching models that blend online with more traditional instruction by helping identify when instructor-student interaction may be most beneficial versus when a synchronous learning environments may be more beneficial because they allow students to self-pace the instruction.

Other principles from Cognitive Load Theory helped guide the design of teaching opportunities that resulted from expanding the worked example across lecture, prelab, and in-lab instruction (Table 2). For example, the split attention effect is a familiar plague of lecture-lab format classrooms (DiBiase 1996), where instruction presents concepts and tools separately. The problem, however, is that it's not particularly easy to present concepts and tools at the same time, or at least in a way that students can hold both in working memory at the same time. The examples of a task hierarchy (Figure 5), sub-task representation (Figure 6), and workflow plan (Figure 7) are attempts to present lecture content that help students develop schemas that integrate kinds of knowledge (strategic and semantic) that are employed when solving problems. Similarly, my decision to not create a video module for any task more than once (Figure 8) connects to both the redundancy effect and the completion effect. The imagination effect supports my strategy of drawing pictures of a problem's functional components (Figure 4) on the blackboard in front of students, rather than showing them prepared slides. It also motivates the strategy of having students plan solutions as a workflow before they interact with the computer to implement the plan. Finally, the strategy of social fading from instructor lead, to collaborative, to independent problem solving reflects the principle of guidance fading and also fosters a participatory learning environment.

\begin{tabular}{|c|c|}
\hline Presentation Strategy & $\begin{array}{l}\text { Cognitive Load } \\
\text { Effect }\end{array}$ \\
\hline $\begin{array}{l}\text { Lessons integrate different kinds of } \\
\text { knowledge }\end{array}$ & Split-attention effect \\
\hline $\begin{array}{l}\text { Video playlist does not teach same tool } \\
\text { twice }\end{array}$ & Redundancy effect \\
\hline $\begin{array}{l}\text { Presentations of concepts with words } \\
\text { and pictures unfold in front of students }\end{array}$ & Imagination effect \\
\hline $\begin{array}{l}\text { Social fading from instructor-lead to } \\
\text { collaborative to independent problem- } \\
\text { solving }\end{array}$ & Guidance fading \\
\hline Video playlist omits some steps & Completion effect \\
\hline
\end{tabular}

Table 2. Connecting presentation strategies to cognitive load effects.

The example provided in this article deals with a problem of spatial analysis with GIS tools. Future research can examine the generalizability of this framework to other domains of cartographic education, including cartographic design, and other tools of cartographic practice, including print-based and web-based technology. This connects to several recent research programs on map design. Discourse analysis of map-making strategies by students (Wiegand 2002) illustrates one method to investigate how students are thinking about making maps. Research on multi-objective decision-making in map design (Xiao and Armstrong 2012) similarly aims to "help novice map makers understand the design process and make cartographic principles more relevant to an expanding community of non-geographers." Expert systems research can help identify if-then rules of cartographic decision making (Buttenfield and Mark 1991; Brus, Dobešová, and Kaňok 2009) that aim to explain reasons for particular actions in a solution. Similarly, a pattern language framework for teaching mapmaking explicitly aims to help students plan and understand reasons for actions in creative design workflows (Howarth 2015).

\section{CONCLUSION}

This ARTICLE PRESENTED A teaching model for problem-based learning with GIS that incorporates findings from studies of expertise and cognitive load theory. I developed a general template for a worked-example that guides learners through three stages of problem solving and apply strategies for managing cognitive load while learning. CLT helped guide my redesign of a teaching model inherited from a senior colleague, providing a basis to keep the parts that should (in theory) work, while also identifying other parts that might make learning more difficult. CLT also raises important questions of the current model that may lead to revisions in the future. For 
example, do the learning goals in my strategy of presenting the worked example in stages add extraneous load? Does the presentation of tools in the context of a problem's solution complicate the transfer of knowledge, creating an Einstellung effect, where the learner is more likely to apply previously constructed schema than create novel solutions?
This article aimed to present the process by which a current teaching model evolved with the hope of encouraging future research that tests strategies for presenting information to learners at the intersection of cognitive theories of learning, spatial thinking, and problem solving.

\section{REFERENCES}

Bartlett, Frederic Charles. 1932. Remembering: A Study in Experimental and Social Psychology. Cambridge: Cambridge University Press.

Brus, J., Z. Dobešová, and J. Kaňok. 2009. “Utilization of Expert Systems in Thematic Cartography." In Intelligent Networking and Collaborative Systems, 28589. Barcelona: IEEE. doi: 10.1109/INCOS.2009.56.

Buttenfield, B. P., and D. M. Mark. 1991. "Expert Systems in Cartographic Design.” Geographic Information Systems, 129-50. doi: 10.1016/ b978-0-08-040277-2.50015-5.

Carroll, William M. 1994. "Using Worked Examples as an Instructional Support in the Algebra Classroom." Journal of Educational Psychology 86(3): 360-67. doi: 10.1037/0022-0663.86.3.360.

Chandler, Paul, and John Sweller. 1991. "Cognitive Load Theory and the Format of Instruction." Cognition and Instruction 8(4): 293-332. doi: 10.1207/ s1532690xci0804_2.

Chi, Michelene T. H., Miriam Bassok, Matthew W. Lewis, Peter Reimann, and Robert Glaser. 1989. "SelfExplanations: How Students Study and Use Examples in Learning to Solve Problems." Cognitive Science 13(2): 145-82. doi: 10.1016/0364-0213(89)90002-5.

Churchill, Robert R., and Phillip Frankland. 1981. "Using Interactive Computer Mapping to Teach Cartographic Concepts at Middlebury College." In Computer Mapping Applications in Urban, State and Federal Government Plus Computer Graphics in Education, edited by Patricia A. Moore, 69-76. Cambridge, MA: Harvard Graduate School of Design.
Cooper, G., S. Tindall-Ford, P. Chandler, and J. Sweller. 2001. "Learning by Imagining." Journal of Experimental Psychology: Applied 7(1): 68-82. doi: 10.1037/1076-898X.7.1.68.

Diamond, Jared M. 1969. “Avifaunal Equilibria and Species Turnover Rates on the Channel Islands of California." Proceedings of the National Academy of Sciences of the United States of America 64(1): 57-63. doi: 10.1073/pnas.64.1.57.

DiBiase, David. 1996. "Rethinking Laboratory Education for an Introductory Course on Geographic Information.” Cartographica 33(4): 61-72. doi: 10.3138/0137-7R27-1701-5417.

DiBiase, David, Michael DeMers, Ann Johnson, Karen Kemp, Ann Taylor Luck, Brandon Plewe, and Elizabeth Wentz, eds. 2006. Geographic Information Science and Technology Body of Knowledge. Washington, DC: Association of American Geographers.

Duncker, Karl. 1945. “On Problem-Solving.” Translated by Lynne S. Lees. Psychological Monographs 58(5): i-113. doi: 10.1037/h0093599.

Ginns, Paul, Paul Chandler, and John Sweller. 2003. "When Imagining Information Is Effective." Contemporary Educational Psychology 28(2): 229-51. doi: 10.1016/S0361-476X(02)00016-4.

Howarth, J. T. 2015. "A Framework for Teaching the Timeless Way of Mapmaking." Cartography and Geographic Information Science 42: 6-10. doi: 10.1080/15230406.2015.1058693.

Kalyuga, Slava, P. Ayres, P. Chandler, and J. Sweller. 2003. "The Expertise Reversal Effect." Educational Psychologist 38(1): 23-31. doi: 10.1207/ S15326985EP3801_4. 
Kalyuga, Slava, Paul Chandler, Juhani Tuovinen, and John Sweller. 2001. "When Problem Solving Is Superior to Studying Worked Examples." Journal of Educational Psychology 93(3): 579-88. doi: 10.1037/0022-0663.93.3.579.

Leahy, Wayne, and John Sweller. 2004. "Cognitive Load and the Imagination Effect." Applied Cognitive Psychology 18(7): 857-75. doi: 10.1002/acp.1061.

Marble, Duane. 1998. "Rebuilding the Top of the Pyramid.” ARC Nerws.

Mayer, Richard E. 1992. Thinking, Problem Solving, Cognition. New York: W. H. Freeman.

2009. Multimedia Learning. Cambridge ; New York: Cambridge University Press. doi: 10.1017/ CBO9780511811678.

ed. 2014. The Cambridge Handbook of Multimedia Learning. Second Edition. New York: Cambridge University Press. doi: 10.1017/cbo9781139547369.

Moreno, Roxana, and Babette Park. 2010. "Cognitive Load Theory: Historical Development and Relation to Other Theories." In Cognitive Load Theory, edited by Jan L. Plass, Roxana Moreno, and Roland Brünken, 9-28. Cambridge; New York: Cambridge University Press. doi: 10.1017/CBO9780511844744.003.

Paas, Fred G. W. C. 1992. "Training Strategies for Attaining Transfer of Problem-Solving Skill in Statistics: A Cognitive-Load Approach.” Journal of Educational Psychology 84(4): 429-34. doi: 10.1037/0022-0663.84.4.429.

Paas, Fred G. W. C., and Jeroen J. G Van Merriënboer. 1994. "Variability of Worked Examples and Transfer of Geometrical Problem-Solving Skills: A CognitiveLoad Approach." Journal of Educational Psychology 86(1): 122-33. doi: 10.1037/0022-0663.86.1.122.

Plass, Jan L., Roxana Moreno, and Roland Brünken, eds. 2010. Cognitive Load Theory. Cambridge ; New York: Cambridge University Press. doi: 10.1017/ CBO9780511844744.
Pólya, George. 1971. How to Solve It; a New Aspect of Mathematical Method. Princeton, NJ: Princeton University Press.

Prager, Steven D. 2011. "Using the GIS\&T Body of Knowledge for Curriculum Design: Different Design for Different Contexts." In Teaching Geographic Information Science and Technology in Higher Education, edited by David J. Unwin, Kenneth E. Foote, Nicholas J. Tate, and David DiBiase, 61-80. John Wiley \& Sons, Ltd. doi: 10.1002/9781119950592.

Quilici, Jill L, and Richard E Mayer. 1996.

"Role of Examples in How Students Learn to Categorize Statistics Word Problems.” Journal of Educational Psychology 88(1): 144-61. doi: 10.1037/0022-0663.88.1.144.

Renkl, Alexander, and Robert K. Atkinson. 2003. "Structuring the Transition From Example Study to Problem Solving in Cognitive Skill Acquisition: A Cognitive Load Perspective." Educational Psychologist 38(1): 15. doi: 10.1207/S15326985EP3801_3.

2010. "Learning from Worked-Out Examples and Problem Solving." In Cognitive Load Theory, edited by Jan L. Plass, Roxana Moreno, and Roland Brünken, 91-108. Cambridge; New York: Cambridge University Press. doi: 10.1017/CBO9780511844744.

Renkl, Alexander, Robert K. Atkinson, Uwe H. Maier, and Richard Staley. 2002. "From Example Study to Problem Solving: Smooth Transitions Help Learning." The Journal of Experimental Education 70(4): 293-315. doi: 10.1080/00220970209599510.

Rourke, Arianne, and John Sweller. 2009. “The Worked-Example Effect Using Ill-Defined Problems: Learning to Recognise Designers' Styles." Learning and Instruction 19(2): 185-99. doi: 10.1016/j. learninstruc.2008.03.006.

Schneider, Walter, and Richard M. Shiffrin. 1977. "Controlled and Automatic Human Information Processing: I. Detection, Search, and Attention." Psychological Review 84(1): 1-66. doi: 10.1037/0033-295X.84.1.1.

Schön, Donald A. 1983. The Reflective Practitioner: How Professionals Think in Action. New York: Basic Books. 
Sfard, Anna. 1998. "On Two Metaphors for Learning and the Dangers of Choosing Just One." Educational Researcher 27(2): 4-13. doi: 10.3102/0013189X027002004.

Sweller, John. 2010. "Cognitive Load Theory: Recent Theoretical Advances." In Cognitive Load Theory, edited by Jan L. Plass, Roxana Moreno, and Roland Brünken, 29-47. Cambridge; New York: Cambridge University Press. doi: 10.1017/CBO9780511844744.004.

Sweller, John, and P Chandler. 1994. "Why Some Material Is Difficult to Learn.” Cognition and Instruction 12(3): 185-233. doi: 10.1207/ s1532690xci1203_1.

Sweller, John, Paul Chandler, Paul Tierney, and Martin Cooper. 1990. "Cognitive Load as a Factor in the Structuring of Technical Material." Journal of Experimental Psychology: General 119(2): 176-92. doi: 10.1037/0096-3445.119.2.176.

Sweller, John, and Graham A. Cooper. 1985. "The Use of Worked Examples as a Substitute for Problem Solving in Learning Algebra." Cognition and Instruction 2(1): 59-89. doi: 10.1207/s1532690xci0201_3.
“The Strawman Report.” 2003. Alexandria, VA: University Consortium for Geographic Information Science.

Tomlin, C. Dana. 1990. Geographic Information Systems and Cartographic Modeling. Englewood Cliffs, NJ: Prentice Hall.

Tuovinen, Juhani E, and John Sweller. 1999. “A Comparison of Cognitive Load Associated with Discovery Learning and Worked Examples." Journal of Educational Psychology 91 (2):334-41. doi: 10.1037/0022-0663.91.2.334.

Ward, Mark, and John Sweller. 1990. "Structuring Effective Worked Examples." Cognition and Instruction 7(1): 1-39. doi: 10.1207/s1532690xci0701_1.

Wiegand, Patrick. 2002. "Analysis of Discourse in Collaborative Cartographic Problem Solving." International Research in Geographical and Environmental Education 11(2): 138-58. doi: 10.1080/10382040208667476. 